IP Periodica Polytechnica

Mechanical Engineering

61(3), pp. 242-246, 2017

https://doi.org/10.3311/PPme.10469

Creative Commons Attribution (i)

RESEARCH ARTICLE

\section{Modelling Blood Pressure in Stenosed Coronary Arteries}

\author{
Viktor Szabó $^{1 *}$, Csaba Jenei², Gábor Halász ${ }^{1}$
}

Received 04 January 2017; accepted 10 March 2017

\begin{abstract}
In this paper a $1 D$ model is presented for the simulation of blood flow in stenosed coronary arteries. The model was developed by implementing a special boundary counditions in a previously published arterial blood flow model. The stenosis as well as the arterioles were modelled as linear resistances. Using patient-specific parameters, blood flow can be calculated for different inlet flow rates. The model was used to simulate blood pressure waveforms of 5 patients diagnosed with coronary stenosis. Simulation results show good agreement with measurement data.
\end{abstract}

Keywords

blood flow, coronary artery diesases, stenosis, 1-D modelling

\section{Introduction}

Cardiovascular diseases (CVDs) are the number 1 cause of death globally [1]. They are caused by atherosclerosis, that is the narrowing and/or blockage of the coronary blood vessels. In the recent years, fractional flow reserve (FFR) has emerged as a reliable index for determining the significance of a coronary stenosis [2]. FFR is the ratio of the distal to the proximal pressure before the stenosis (Eq. (1)). In clinical trials, the value of FFR below 0.8 is generally recommended as a threshold for a revascularisation [3].

$$
F F R=\frac{\overline{p_{\text {dist }}}}{\overline{p_{p r o x}}}
$$

Recent studies suggest that not only the value of FFR but also the blood pressure waveform contains important information about the nature of the flow in a stenosed coronary artery [4-6]. In this paper, we present a 1D model for the simulation of blood pressure waveforms in stenosed coronary arteries. The model is based on a previously published model used to simulate blood flow in the human arterial network [7].

\section{Models and methods}

The blood is treated as a Newtonian fluid and the viscoelastic behaviour of the vessel wall is modelled by the so called Stuart model, a useful tool for modelling viscoelasticity in polymer technology [8]. As the detailed description of the model has been published earlier [7], only a summary is presented below.

In the original model, pressure and velocity distribution and wall deformation for each vessel is calculated by solving the following system of partial differential equations simultaneously using the method of characteristics:

1. Momentum equation

$$
\frac{\partial v}{\partial t}+v \frac{\partial v}{\partial x}+\frac{1}{\rho} \frac{\partial p}{\partial x}+g \frac{d h}{d x}+\frac{32 v}{D^{2}} v=0
$$

2. Modified continuity equation:

$$
2 \frac{\partial \varepsilon}{\partial t}+2 v \frac{\partial \varepsilon}{\partial x}+(2 \varepsilon+1) \frac{\partial v}{\partial x}=0
$$

3. Equations of the Stuart model:

$$
2 \frac{\partial \varepsilon}{\partial t}+2 v \frac{\partial \varepsilon}{\partial x}+(2 \varepsilon+1) \frac{\partial v}{\partial x}=0
$$




$$
\begin{gathered}
\frac{p D_{0}}{2 \delta_{0}}(2 \varepsilon+1)=E_{2} \varepsilon_{2}+\eta_{2} \dot{\varepsilon}_{2} \\
\varepsilon=\varepsilon_{1}+\varepsilon_{2}
\end{gathered}
$$

where $D_{0}$ and $D$ are the initial and instantaneous diameters, $p$ the transmural pressure, $v$ the axial velocity, $h$ the elevation, $\delta_{0}$ the wall thickness, $v$ the kinematic viscosity, $g$ the gravitational acceleration and $\rho$ the density of the blood, $E_{1}$, $E_{2}$ and $\eta_{2}$ material properties of the vessel, and $\varepsilon_{1}, \varepsilon_{2}$ and $\varepsilon$ represent the elastic, the viscoelastic and the total deformation of the vessel wall, respectively.

Earlier studies indicate that cardiac motion does not have a significant effect on coronary blood flow $[9,10]$ therefore it is enough to consider a static arterial network.

\subsection{Boundary Conditions}

At the inlet, the proximal pressure was used as a periodic boundary condition. The stenosis as well as the arterioles were taken into account using the linear resistance model:

$$
\Delta p=\rho \varsigma Q=R Q
$$

where $\Delta p$ is the pressure drop at the stenosis (as well as at the outlet), $\rho$ the blood density, $\varsigma$ the resistance term, $R$ the resistance and $Q$ the blood flow.

The original model has been successfully used when the linear resistance at the outlet was constant [11]. Coronary arteries, however, are squeezed by the heart during contraction. Therefore either time-varying peripheral resistance or time-varying pressure should be prescribed at the outlet. Calculating timevarying resistance for the 5 patients did not prove to be useful therefore we applied time-varying pressure at the outlet.

The myocardial pressure $p_{\text {myo }}$ at the outlet was calculated from the pressure in the left ventricle $p_{L V}$. Ghista has used an analytic model to approximate ventricular radial stress as a function of $p_{L V}$. Using this approximation, the average stress was $0.4 \cdot p_{L V}[12]$. In our model, the average myocardial pressure was approximated by the average stress, that is:

$$
p_{\text {myo }}=0.44 \cdot p_{L V}
$$

To calculate the value of $p_{L V}$, the so-called time-varying elastance model was used, which was first introduced by Suga [13] and was first applied to the coronary circulation by Krams [14]. It has been successfully used in earlier studies for the modelling of the left ventricle $[15,16]$. In this model the ventricular elastance $E_{L V}$ is defined as the ratio of $p_{L V}$ to the left ventricular volume $V_{L V}$, corrected for a "dead volume" $V_{0}$, the volume in the ventricle at zero pressure:

$$
E_{L V}(t)=\frac{p_{L V}(t)}{V_{L V}(t)-V_{0}}
$$

The left ventricular pressure is calculated in each cardiac phase differently [17]. The different phases can be seen in Fig. 1.



Fig. 1 Phases of the cardiac cycle (adapted from [18])

Phase I - Isovolumetric contraction: The beginning phase of the contraction lasts between the closing of the mitral valve (a) and the opening of the aortic valve (b). During this phase the left ventricle is completely full and its volume is maximal, therefore $p_{L V}$ can be calculated using the following formula:

$$
p_{L V}(t)=E_{L V}(t) \cdot\left(V_{\max }-V_{0}\right)
$$

Several models can be used to approximate elastance during this phase. For the studied patients best results were achieved using the sinusoid approximation [17]:

$$
E_{L V}(t)=E_{\max } \cdot \sin \left(\frac{t \pi}{2 T_{\text {rise }}}\right)
$$

where $T_{\text {rise }}$ is ca. $83 \%$ of the duration of systole and $E_{\max }$ is the ratio between the blood pressure measured during the closing of the aortic valve (c) and the minimal volume difference:

$$
E_{\max }=\frac{p_{c}}{V_{\min }-V_{0}}
$$

Phase II - Ventricular ejection: This phase lasts between at the opening (b) and the closing (c) of the aortic valve during systole. During this phase the pressure in the ventricle is similar to the aortic pressure, and therefore can be used for estimating $p_{L V}$.

Phase III - Isovolumetric relaxation: This phase lasts between the closing of the aortic valve (c) and the opening of the mitral valve (d) during early diastole. During this phase the volume of left ventricle is minimal, and therefore $p_{L V}$ is calculated using the following formula:

$$
p_{L V}(t)=E_{L V}(t) \cdot\left(V_{\min }-V_{0}\right)
$$

Elastance is calculated using the sinusoid approximation [17]:

$$
E_{L V}(t)=E_{\max } \cdot\left(1-\sin \left(\frac{\left(t-T_{\text {rise }}\right) \pi}{2 T_{\text {fall }}}\right)\right)
$$

where $T_{\text {fall }}$ is ca. $17 \%$ of the duration of systole and $E_{\max }$ is calculated similar to Phase I. 
Phase IV - Ventricular filling: This phase lasts between the opening (d) and the closing (a) of the mitral valve during diastole. During this phase the left ventricular pressure is approximately 0 , and therefore the elastance is 0 .

The minimal volume of the left ventricle $V_{\min }$ was set to 40 $\mathrm{ml}$, and the maximal volume $V_{\max }$ to $120 \mathrm{ml}$. These values did not have significant effect on the results. Using the pressure at the opening and closing of the aortic valve during systole - that is at (b) and (c) in Fig. 1, respectively, the value of $V_{0}$ can be calculated as:

$$
V_{0}=\frac{p_{b} V_{\min }-E_{b} p_{c} V_{\max }}{p_{b}-E_{b} p_{c}}
$$

where $E_{b}$ is the normalized elastance that is calculated at (b) in Fig. 1:

$$
E_{b}=\sin \left(\frac{t_{b} \pi}{2 T_{\text {rise }}}\right)
$$

The graph of $E_{b}$ normalized by $E_{\max }$ for patient BME1 can be seen in Fig. 2.



Fig. 2 Normalized elastance for patient BME1

\section{Measurement data}

Consecutive patients were studied with a wide range of suspected or known coronary artery diseases, which were referred to the Hemodynamic Laboratory of University of Debrecen, Department of Cardiology and Cardiac Surgery. All patients underwent a diagnostic coronary angiography at the centre according to the local protocol.

All clinical and procedural data were prospectively stored in a dedicated electronic database and were retrospectively analyzed in this study. Coronary angiographies were performed through the radial or femoral access according to the feasibility of the radial approach or the patient suitability and operator preference.

All patients gave written informed consent to the invasive procedure in accordance with the protocol approved by the local ethics committee.
The geometry of 5 stenosed coronary vessels were acquired via CT angiography. Average diameter and length was calculated from CT-data. In addition, proximal and distal blood pressure were measured, from which the value of FFR was determined.

For each patient, blood flow was calculated using vessel geometry and the propagation speed of the contrast dye. FFR and blood flow values for each patient can be seen in Table 1 .

Using measurement data, the value of stenosis resistance $R_{\text {sten }}$ and terminal resistance $R_{\text {term }}$ was calculated in the following way: first, the average value of the total pressure drop $\Delta p_{\text {total }}$ was calculated as the difference between the average proximal pressure and the average myocardial pressure:

$$
\Delta p_{\text {total }}=\overline{p_{\text {prox }}}-\overline{p_{\text {myo }}}=\overline{p_{\text {prox }}}-0.44 \cdot \overline{p_{L V}}
$$

The pressure drop is caused by the resistance at the stenosis and the terminal site as well as the friction loss along the vessel $\left(\Delta p_{\text {fric }}\right)$. After decreasing the total pressure loss by the friction loss, the sum of the stenosis and terminal resistance can be calculated as the ratio of the remaining pressure loss to the average blood flow $Q$ :

$$
R_{\text {sten }}+R_{\text {term }}=\frac{\Delta p_{\text {total }}-\Delta p_{\text {fric }}}{Q}
$$

The sum of the resistances can be determined after calculating the value of the right hand side of the formula. Next, the sum was divided into two parts so that the distal blood pressure and the average blood flow calculated from the simulation results would approximate the measured data.

\section{Results}

The values of resistances and the measured as well as the calculated FFR values can be seen in Table 1 and Table 2. Significant differences could be observed between the resistance values for each patient. Calculated FFR values and blood flow showed very good agreement with measurement data. The root mean squared error (RMSE) between measured and calculated distal blood pressure was less than $9 \mathrm{mmHg}$ for each patient, which accounted for $3-13 \%$ of the average distal pressure.

Measured and calculated distal blood pressure graphs can be seen in Fig. 3.a)-d) and Fig. 4. Qualitative agreement was found for each patient. The agreement was very good in case of patients BME1, BME2 and BME4.

Table 1 Measured and calculated values of FFR and blood flow

\begin{tabular}{lcccc}
\hline \multirow{2}{*}{ Patient } & \multicolumn{2}{c}{ Q $(\mathrm{ml} / \mathrm{s})$} & \multicolumn{2}{c}{ FFR (-) } \\
\cline { 2 - 5 } & Measured & Calculated & Measured & Calculated \\
\hline BME1 & 2.88 & 2.89 & 0.53 & 0.53 \\
BME2 & 3.49 & 3.48 & 0.87 & 0.85 \\
BME3 & 3.21 & 3.23 & 0.81 & 0.84 \\
BME4 & 2.73 & 2.79 & 0.93 & 0.92 \\
BME10 & 4.66 & 4.65 & 0.73 & 0.73 \\
\hline
\end{tabular}


BME1

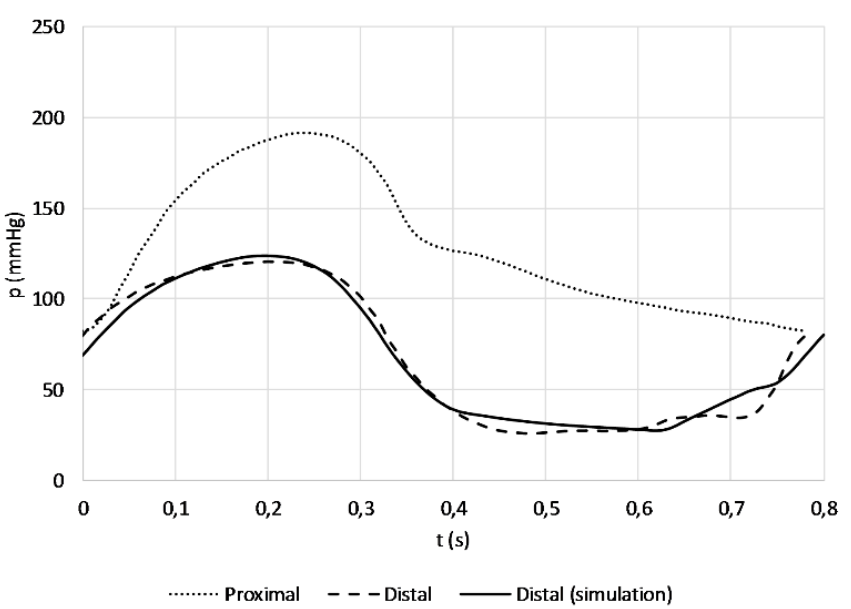

BME3

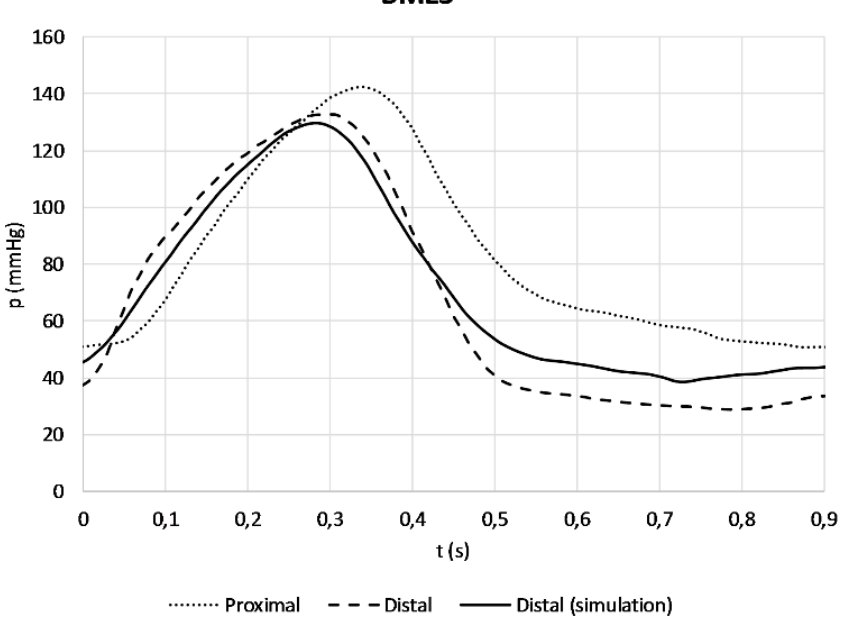

BME2

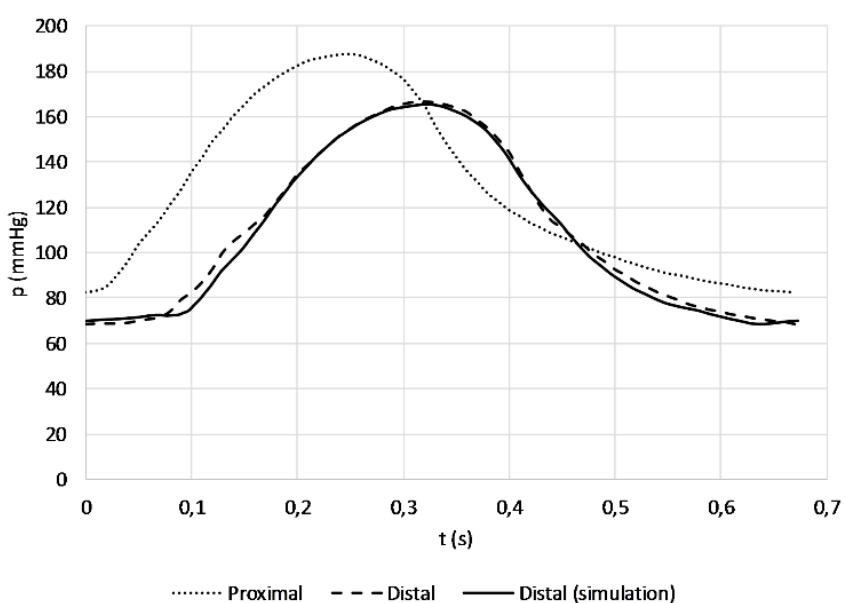

BME4

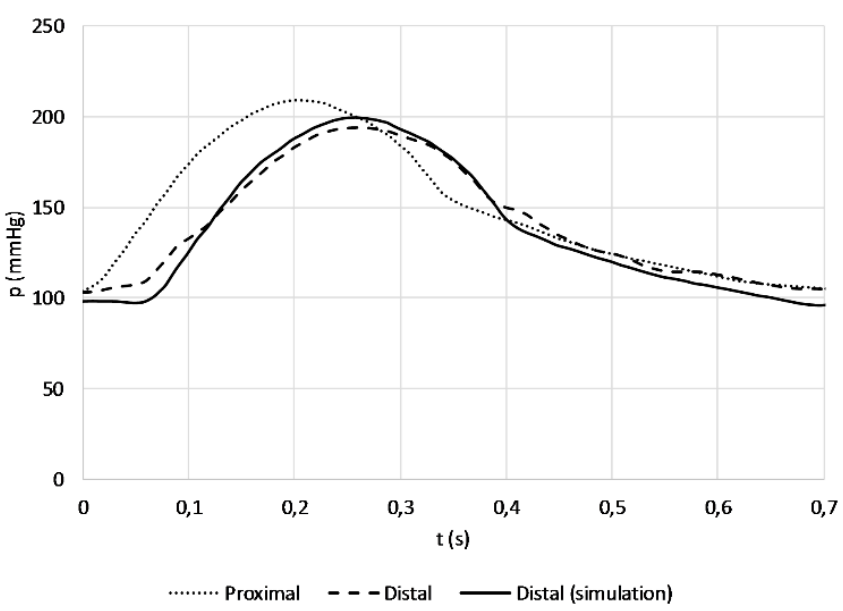

Fig. 3 a)-d) Proximal and distal pressures of patients BME1-BME4

Table 2 Resistance and error values

\begin{tabular}{lccc}
\hline Patient & $\mathrm{R}_{\text {sten }}\left(\mathrm{Ns} / \mathrm{m}^{5}\right)$ & $\mathrm{R}_{\text {term }}\left(\mathrm{Ns} / \mathrm{m}^{5}\right)$ & $\mathrm{RMSE}(\mathrm{mmHg})$ \\
\hline BME1 & $1.73 \mathrm{E}+09$ & $1.49 \mathrm{E}+09$ & $5.40(8 \%)$ \\
BME2 & $5.25 \mathrm{E}+08$ & $2.49 \mathrm{E}+09$ & $2.91(3 \%)$ \\
BME3 & $1.05 \mathrm{E}+08$ & $1.79 \mathrm{E}+09$ & $8.81(13 \%)$ \\
BME4 & $3.15 \mathrm{E}+08$ & $4.52 \mathrm{E}+09$ & $6.94(5 \%)$ \\
BME10 & $3.78 \mathrm{E}+08$ & $9.98 \mathrm{E}+08$ & $4.45(8 \%)$ \\
\hline
\end{tabular}

\section{Discussion}

The model presented above can be used to approximate distal blood pressure in stenosed coronary arteries. The model is based on a previously published numerical method, which can be used for the simulation of blood flow in the human arterial network.

For the simulation, patient-specific parameters were used based on the vessel geometry and measurement data. Elastic properties of the vessel also has an effect on the distal blood pressure graph but up to $50 \%$ changes in the value ofs the elastic modulus had little effect on the results.

One of the main advantages of this model is that, using patient-specific parameters, the distal blood pressure can be

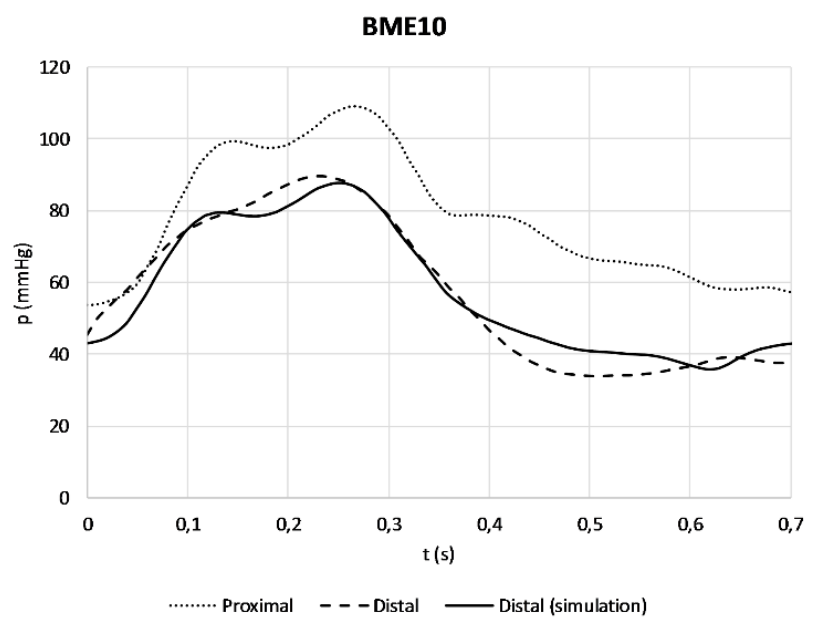

Fig. 4 Proximal and distal pressures of patient BME10

calculated for different values of average blood flow at the inlet. The average simulation time is less than 2 minutes on a personal computer which makes it possible to perform parameter studies and analyze the effect of blood flow on the distal blood pressure. This can provide useful information for medical research. 


\section{References}

[1] WHO, Cardiovascular diseases (CVDs). 2016. [Online]. Available from: http:/www.who.int/mediacentre/factsheets/fs317/en/ [Accessed: 3rd January 2017]

[2] Pijls, N. H .J., Fearon, W. F., Tonino, P. A. L., Siebert, U., Ikeno, F., Bornschein, B., van't Veer, M., Klauss, V., Manoharan, G., Engstrøm, T., Oldroyd, K. G., Ver Lee, P. N., McCarthy, P. A., De Bruyne, B. "Fractional flow reserve versus angiography for guiding percutaneous coronary intervention in patients with multivessel coronary artery disease: 2-year follow-up of the FAME (Fractional Flow Reserve Versus Angiography for Multivessel Evaluation) study." Journal of the American College of Cardiology. 56(3), pp. 177-84. 2010.

https://doi.org/10.1016/j.jacc.2010.04.012

[3] De Bruyne, B., Pijls, N. H., Bartunek, J., Kulecki, K., Bech, J. W., De Winter, H., Van Crombrugge, P., Heyndrickx, G. R., Wijns, W. "Fractional flow reserve in patients with prior myocardial infarction." Circulation. 104(2), pp. 157-162. 2001. https://doi.org/10.1161/01.CIR.104.2.157

[4] Kőszegi, Z., Jenei, C., Sánta, J., Tar, B. "Relation between fractional flow reserve and the intracoronary pressure waveform." EuroPCR, 2015. URL: https://www.pcronline.com/eurointervention/AbstractsEuroPCR2015/abstracts-europcr-2015/OP114/relation-between-fractionalflow-reserve-and-the-intracoronary-pressure-waveform.html

[5] Vavuranakis, M., Stamatopoulos, I., Papaioannou, T. G., Nikolopoulos, S., Toutouzas, K., Stefanadis, C., Vavuranakis, M. "Alterations of pressure waveforms along the coronary arteries and the effect of microcirculatory vasodilation." International Journal of Cardiology. 117(2), pp. 254-259. 2007.

[6] Lugosi, P., Sánta, J., Sánta, P. "Nonhyperemic intracoronary pressure waveform analysis predicts the fractional flow reserve." In: $2010 \mathrm{Com}$ puting in Cardiology, Belfast, 2010, pp. 1079-1082.

[7] Bárdossy, G., Halász, G. "Modeling blood flow in the arterial system." Periodica Polytechnica Mechanical Engineering. 55(1), pp. 49-51. 2011. https://doi.org/10.3311/pp.me.2011-1.07

[8] Bodor, G., Vas, L. M. "Polimer anyagszerkezettan." (Polymer Materials Science.) Műegyetemi Kiadó, Budapest. 2000. (in Hungarian).

[9] Szabó, V., Halász, G. "Effect of cardiac motion on coronary blood flow." In: OGET 2016 - 24th International Conference on Mechanical Enginering. Deva, Romania, 2016. pp. 398-401. (in Hungarian)
[10] Zeng, D., Ding, Z., Friedman, M. H., Ethier, C. R. "Effects of cardiac motion on right coronary artery hemodynamics." Annals of Biomedical Engineering. 31(4), pp.420-429.

[11] Bárdossy, G., Halász, G. "A "backward" calculation method for the estimation of central aortic pressure wave in a 1D arterial model network." Computers \& Fluids. 73, pp. 134-144. 2013.

https://doi.org/10.1016/j.compfluid.2012.12.014

[12] Ghista, D. N., Zhong, L., Tan, R.-S., Ng, E. Y. K. "Left Ventricular Filling Performance Characteristics." In D. Ghista, D., Ng, E. (eds.) Cardiac perfusion and pumping engineering. (pp. 191-213.), World Scientific Publishing Company Pte Limited, Singapore, 2007.

[13] Suga, H., Sagawa, K., Shoukas, A. A. "Load Independence of the Instantaneous Pressure-Volume Ratio of the Canine Left Ventricle and Effects of Epinephrine and Heart Rate on the Ratio." Circulation Research. 32(3), pp. 314-322. 1973.

[14] Krams, R., Sipkema, P., Westerhof, N. "Varying elastance concept may explain coronary systolic flow impediment." The American Journal of Physiology. 257(5), pp. H1471-H1479. 1989.

[15] Reymond, P., Merenda, F., Perren, F., Rüfenacht, D., Stergiopulos, N. "Validation of a one-dimensional model of the systemic arterial tree." American Journal of Physiology. Heart and Circulatory Physiology. 297(1), pp. H208-H222. 2009.

https://doi.org/10.1152/ajpheart.00037.2009

[16] Mynard, J. P., Smolich, J. J. "One-Dimensional Haemodynamic Modeling and Wave Dynamics in the Entire Adult Circulation." Annals of Biomedical Engineering. 43(6), pp. 1443-1460. 2015.

https://doi.org/10.1007/s10439-015-1313-8

[17] Vandenberghe, S., Segers, P., Verdonck, P. "Mathematical Modeling of Ventricular-Assist Devices." In: Ghista, D. N., Ng, E. Y.-K. (eds.) Cardiac perfusion and pumping engineering. (pp. 419-475.) World Scientific Publishing, Singapore. 2007.

[18] Fonyó, A. "Az orvosi élettan tankönyve." (Medical Physiology Textbook.) Medicina Könyvkiadó, Budapest. 2011. URL: http://www.tankonyvtar.hu/hu/tartalom/tamop425/2011_0001_524_Elettan/adatok.html 